\title{
Mirror therapy: A potential intervention for pain management
}

\author{
Priscilla G. WittKopf ${ }^{1 *}$, Mark I. Johnson ${ }^{2}$ \\ ${ }^{1}$ MSc. Centre for Pain Research, School of Clinical and Applied Sciences, Leeds Beckett University and Leeds Pallium Research Group, Leeds, United Kingdom \\ ${ }^{2}$ PhD. Centre for Pain Research, School of Clinical and Applied Sciences, Leeds Beckett University and Leeds Pallium Research Group, Leeds, United Kingdom
}

\section{SUMMARY}

The consequences of chronic pain and associated disabilities to the patient and to the health care system are well known. Medication is often the first treatment of choice for chronic pain, although side effects and high costs restrict long-term use. Inexpensive, safe and easy to self-administer non-pharmacological therapies, such as mirror therapy, are recommended as adjuncts to pain treatment. The purpose of this review is to describe the principles of use of mirror therapy so it can be incorporated into a health care delivery. The physiological rationale of mirror therapy for the management of pain and the evidence of clinical efficacy based on recent systematic reviews are also discussed. Mirror therapy, whereby a mirror is placed in a position so that the patient can view a reflection of a body part, has been used to treat phantom limb pain, complex regional pain syndrome, neuropathy and low back pain. Research evidence suggests that a course of treatment (four weeks) of mirror therapy may reduce chronic pain. Contraindications and side effects are few. The mechanism of action of mirror therapy remains uncertain, with reintegration of motor and sensory systems, restored body image and control over fear-avoidance likely to influence outcome. The evidence for clinical efficacy of mirror therapy is encouraging, but not yet definitive. Nevertheless, mirror therapy is inexpensive, safe and easy for the patient to self-administer.

Keywords: chronic pain, self care, pain/physiopathology/psychology.

\section{INTRODUCTION}

Chronic pain is a global healthcare problem affecting developed and developing countries. A systematic review estimated that the weighted mean prevalence of chronic pain in the adult population worldwide may be as high as $30.3 \%$ (19 studies, 65 surveys, 34 countries, and 182,019 respondents). ${ }^{1}$ Data from Brazil suggests that the prevalence of chronic pain in the adult population can be as high as $42 \%{ }^{2}$ The economic burden of chronic pain is greater than that of many other illnesses and diseases because of the high cost to health care and to social security services.

Pharmacological interventions are most commonly used as the first-line treatment for chronic pain, although side effects and high costs mitigate long-term use. For example, chronic use of acetaminophen may cause hepatotoxicity; NSAIDs may cause gastrointestinal renal disturbances and a risk of bleeding; and opioids may cause respiratory depression, urinary retention, constipation, nausea and cognitive impairment. Rehabilitation tech- niques are often used as stand-alone treatments or as adjuncts to pharmacological treatments and include physical activity and exercise, manual therapy, acupuncture, thermal therapy and electrotherapy such as transcutaneous electrical nerve stimulation (TENS). ${ }^{3}$ The World Health Organization (WHO) supports the use of rehabilitation techniques that are inexpensive, safe and easy to self-administer in order to reduce healthcare costs and empower individuals to manage their own pain which is known to improve outcome. ${ }^{3}$

A rehabilitation technique that proved promising in recent years is mirror therapy, which involves a mirror being placed in a position that allows the patient to view a reflection of a body part. Mirror therapy is most commonly used to relieve pain in limbs by hiding the painful limb behind the mirror (out of view) whilst the nonpainful limb is placed in front of the mirror so that it creates a reflection that can be seen by the patient. Thus, the patient can observe a reflection of the non-painful limb so that it appears to be in the same position as the 
painful limb (which is out of view) (Figure 1). In amputees, this creates the illusion of having two intact limbs. ${ }^{4}$ In individuals with inflamed limbs that appear swollen and red (e.g. complex regional pain syndrome) it creates the illusion of having a "healthy-looking" limb. ${ }^{5}$ Often patients are reluctant to move painful limbs, creating pain behaviors dominated by fear and avoidance of movement. Mirror therapy can be used to create a reflection of a normally moving healthy limb that is located in the same place in space as the painful limb hidden behind the mirror. This gives the illusion that the painful limb can move normally too.

Mirror therapy can be used as a stand-alone therapy or in combination with other pain-relieving techniques. Mirror therapy has been incorporated into therapeutic programs to treat painful conditions resulting from neuropathy complex regional pain syndrome and non-specific mechanical back pain. ${ }^{6,7}$ It has also been used to improve functional outcomes after stroke. ${ }^{8}$

Mirror therapy is not frequently used to treat chronic pain in Brazil, although it has been suggested that mirror therapy could be inserted in a continuous rehabilitation program to modify behavior to improve movement and alleviate pain. ${ }^{5,9,10}$

The purpose of this review is to describe the principles of use of mirror therapy so it can be incorporated into a health-care delivery. The physiological rationale of mirror therapy for the management of chronic pain and evidence of clinical efficacy based on recent systematic reviews are also discussed.

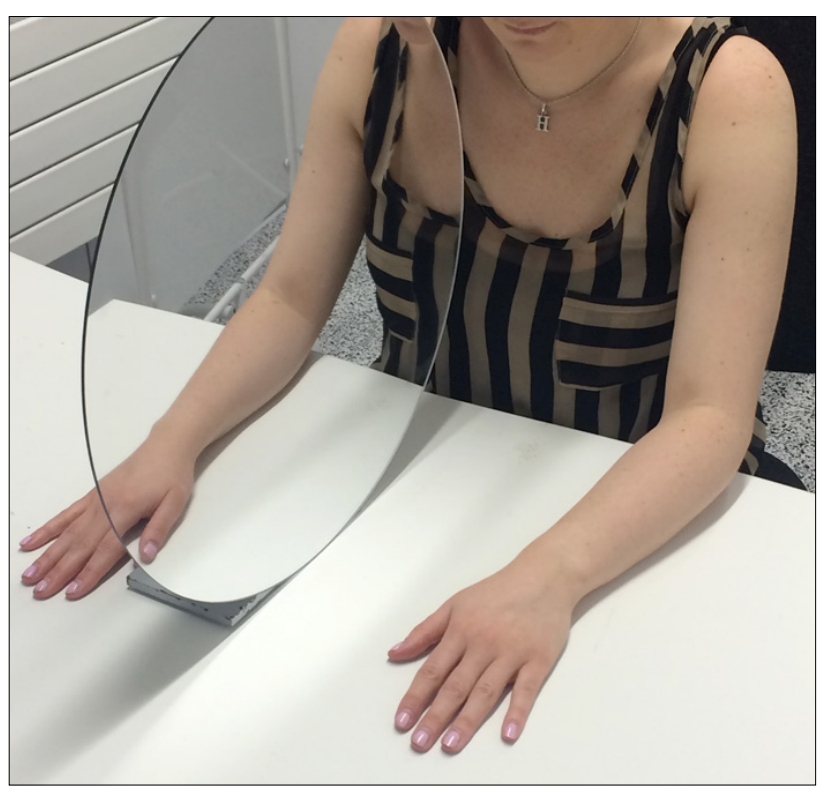

FIGURE 1 Positioning for upper limb mirror therapy.

\section{Principles OF USE}

During mirror therapy the patient should be seated comfortably with the mirror positioned between their affected and unaffected limbs. Patients are asked to align the reflection of their unaffected limb with the position of their affected limb, so that the reflection appears as if it is in the same location as the affected limb hidden behind the mirror. The mirror should be sufficiently large to observe the reflected limb whilst it moves without observing the limb behind the mirror. ${ }^{5}$ Rehabilitation departments usually have mirrors with stands. In their absence, portable mirrors can be used; they are relatively inexpensive and can be purchased over the counter and via the internet without prescription at a cost of approximately U\$10.00. It is important that the mirror is easily accessible, to encourage the patient to use it and that it has a good reflection quality and is not bent, to prevent blurry or distorted reflections. It is advisable to remove jewelry from limbs as much as possible before treatment.

Treatment begins with an adaptive phase, where the patient looks at the reflection without moving the limbs. The reflection of the healthy limb may feel as if it has been perceptually embodied into the patient's body schema so that they get a sense that the reflected limb is their real limb. Perceptual embodiment is the subjective sense of one's body, including a sense of ownership of body parts. Some patients have difficulty experiencing embodiment, and in this situation the therapist can facilitate the process by instructing the patient to imagine that they are looking through a glass instead of a mirror. Another option is to start with a passive sensory stimulus with slow and easy to achieve bilateral movements whilst the patient observes the reflection. ${ }^{9}$ Then the therapist encourages the patient to move their affected limb, which is hidden from view, in synchrony with the unaffected limb. For those in whom movement of the affected limb is not possible, or if pain or stiffness limit the duration of movement, the patient should just look at the reflected image of the unaffected limb until the patient feels ready to progress to movements. ${ }^{5}$ Patients are told that outcomes improve by regularly repeating the technique over time and they are encouraged to perform mirror therapy daily as part of a self-administered home treatment programme. ${ }^{9} \mathrm{Mir}-$ ror therapy should be performed for short periods of time and often, for example, five minute sessions, five to six times per day. A single half hour session once a day or once a week is not encouraged. A diary where the patient documents time using the mirror, types of movements, symptoms and outcomes can be a useful aid to sustain adherence to the treatment regimen. ${ }^{10}$ 
Side effects to mirror therapy are motor extinction, increased pain, exacerbation of movement disorders, confusion and dizziness. ${ }^{11}$ Treatment is discontinued and contraindicated if any of these occur during a course of mirror therapy.

\section{Physiological rationale}

Mirror therapy was first described in 1995 by Ramachandran et al. ${ }^{4}$ They used a mirror to create the illusion that an amputated limb appeared fully intact when an individual observed a reflection of their intact limb in a mirror (i.e. mirror visual feedback). Generally, reflections of normal-sized limbs are used, although mirrors, lenses, binoculars and virtual reality have been used to magnify and minify the visual appearance of painful body parts. ${ }^{12}$

Mirror therapy is commonly used to decrease anxiety, fear of movement and perceived threat associated with movement of painful body parts. This is achieved by creating a visual illusion of a normally-moving healthy limb located in the same place in space as the painful limb hidden behind the mirror. The visual feedback of a normal moving limb breaks the link between pain and fear of movement. ${ }^{6,8}$

It has been suggested that pain relief associated with mirror therapy results from manipulation of sensory and motor integration within the central nervous system. ${ }^{4,8}$ During movement, sensory information is used to compare intention with performance, and motor commands are updated to adjust for discrepancies, ensuring movement matches intention. Motor signals associated with intended movement are sent not only to muscles but also to higher centers within the central nervous system, as an efference copy, to prepare for the consequence of the motor output and to compare with sensory information arising from actual movement (Figure 2). It has been suggested that some painful conditions can be mediated, in part, by incongruence of sensory and motor information. Mirror therapy provides corrective sensory feedback to restore congruence between motor output and sensory input. ${ }^{4,8}$

Mirror therapy has also been used to correct disruptions of body image (body schema) associated with pain when, for example, patients feel as if body parts are large, twisted, heavy and swollen (e.g. complex regional pain syndrome and phantom limb pain) or small and withered (e.g. osteoarthritic hands). ${ }^{13}$ Research suggests that painful disruptions in body image are associated with re-organization of neural circuits in the brain due to disrupted somatosensory input from the body part. Mirror therapy is used to provide a corrective visual representation of the affected body part to facilitate reorganization of brain circuits back to their pre-pain state. ${ }^{8,13}$

Mirror therapy can be used to create a sense of a healthy limb. Painful conditions disturb body image and disrupt an individual's sense of ownership of their painful body part. ${ }^{13} \mathrm{~A}$ sense of ownership of body parts has been investigated using the rubber hand illusion whereby an individual observes a rubber hand being stroked with a brush (in view) whilst their real hand is stroked in synchrony but out of view. Eventually, usually within a few minutes, the sensation of stroking feels as if it arises from the rubber hand and the individual experiences a sense that the rubber hand is part of their body (i.e. embodiment of the rubber hand into the body schema). This embodiment of the rubber hand is accompanied by a sense of "loss" (disembodiment) of the real hand and it is accompanied by physiological responses such as local skin cooling, proprioceptive drift and alterations of neural activity in the brain. ${ }^{13}$ The use of mirror therapy to induce the embodiment of the healthy reflected limb may help to disembody the painful limb, thereby reducing sensory input and pain. ${ }^{5}$

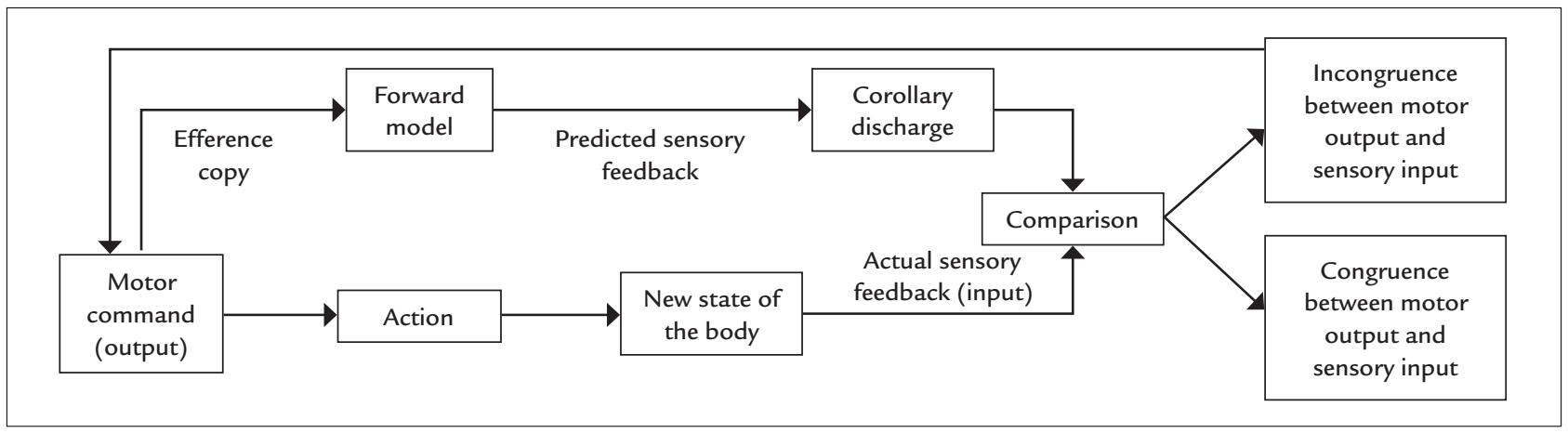

FIGURE 2 Mechanisms involved with motor control. Based on the efference copy of the motor command, a forward model predicts the result of the action. The prediction (corollary discharge) is compared with the information coming from sensory systems, which indicates the new state of the body. 


\section{Clinical efficacy}

According to Grant and Booth, ${ }^{14}$ our review is classified as an overview, which is a summary of the medical literature that attempts to survey the literature and describe its characteristics. Recently, a number of systematic reviews of randomized controlled clinical trials (RCTs) evaluating the effect of mirror therapy on pain have been published. A summary of the studies included in the systematic reviews is provided in Table 1.

The first systematic review to be published was inconclusive due to the heterogeneity and low quality of included studies. ${ }^{15}$ Rothgangel et al..$^{15}$ included six RCTs evaluating the effect of mirror therapy on phantom limb pain, complex regional pain syndrome and pain after stroke. Four of these RCTs (123 participants) evaluated mirror therapy as a stand-alone treatment and all found pain reduction compared with covered mirror control, mental practice or direct observation of the affected limb. ${ }^{16-19}$ Two RCTs (64 participants) used mirror therapy in combination graded motor imagery techniques such as limb laterality recognition and mental practice and both found a reduction of pain intensity compared with usual physiotherapy care..$^{20,21}$

The first meta-analysis of data from RCTs evaluating mirror therapy was conducted as part of a larger review on the effects of graded motor imagery. ${ }^{22}$ Bowering et al. ${ }^{22}$ concluded that graded motor imagery and mirror therapy alone may be effective for a variety of chronic pain conditions. The meta-analysis consisted of data from three RCTs (86 participants) and found no effect of mirror therapy on pain when used as a stand-alone treatment. Control groups included direct view of both hands ${ }^{23}$ and covered mirrors. ${ }^{16-18}$ When used in combination with graded motor imagery, mirror therapy was found to produce a large effect size (standardized mean difference $=1.06 ; 95 \% \mathrm{CI}$ 0.41-1.71; $\mathrm{p}=0.001$ ) on pain reduction in comparison to usual physiotherapy care (63 participants). ${ }^{20,21}$

More recently, Thieme et al. ${ }^{24}$ published a systematic review with a meta-analysis of data from eight RCTs (224 participants), including five additional RCTs to the previous review..$^{22}$ Conditions included complex regional pain syndrome, ${ }^{25}$ phantom limb pain ${ }^{18,26}$ and pain after stroke. ${ }^{16,17,19,23,27}$ Results indicated that mirror therapy reduced pain in the affected limb (standardized mean difference $=-1.00 ; 95 \%$ CI -1.77 to $-0.24 ; \mathrm{p}=0.01$ ) when compared with covered mirror, direct view of both limbs, no treatment and repetitive transcranial magnetic stimulation.

Boesch et al. ${ }^{7}$ meta-analyzed data from one RCT, one non-randomized controlled trial and one within subject comparison study (97 participants) to evaluate the effect of one session of mirror therapy on phantom limb pain ${ }^{28,29}$ and complex regional pain syndrome. ${ }^{30}$ Boesch et al. ${ }^{7}$ did not detect differences from no treatment or covered mirror controls, but their meta-analysis of two RCTs on the effect of a course of mirror therapy lasting four weeks resulted in a large significant reduction (standard mean difference $=-1.11 ; 95 \%$ CI -1.66 to $-0.56 ; \mathrm{p}<0.0001$ ) in phantom limb and complex regional pain syndrome compared with covered mirror therapy. ${ }^{16,18}$ The analgesic effect of mirror therapy was maintained over time ranging from 2 to 6 months.

An RCT of 30 individuals with complex regional pain syndrome has been published after these systematic reviews and the authors concluded that mirror therapy, when used as an adjunct to conventional stroke rehabilitation over the course of four weeks, reduced pain intensity when compared to conventional stroke rehabilitation alone. ${ }^{31}$

There are also RCTs on the efficacy of mirror therapy for back pain, although there are no systematic reviews to date. Wand et al. ${ }^{6}$ placed one large mobile mirror in front of the participant and one mirror behind the participant so that there was a clear view of the reflection of their back. They found that pain intensity was reduced immediately post exercise compared with no reflection control during repeated lumbar movements (mean difference $=9.3 \mathrm{~mm} ; 95 \% \mathrm{CI} 2.8-15.7 ; \mathrm{p}=0.007 ; 25$ participants). The duration of low back pain elicited was also shown to be significantly reduced in the mirror condition (mean difference $=49.9 \mathrm{~s} ; 95 \% \mathrm{CI} 19.3-80.6 ; \mathrm{p}=0.003$ ).

\section{Conclusion}

Mirror therapy has been used in clinical practice for over two decades but it is still not widely accepted as a treatment option in Brazil. At present, there are no evidencebased treatment protocols for mirror therapy to be used in clinical settings because of a lack of studies investigating clinical indications, treatment duration and frequency, or characteristics of mirror therapy intervention. This means that techniques are likely to vary considerably among practitioners and patients. Evidence for clinical efficacy is encouraging but not yet definitive. Nevertheless, mirror therapy is inexpensive, safe and easy for the patient to self-administer following initial training. Contraindications and side effects are few. These characteristics make mirror therapy a potential treatment option for pain management.

\section{Conflict of interest}

The authors declare no conflict of interest. 
TABLE 1 Description of studies included in the systematic reviews investigating the effect of mirror therapy on pain.

\begin{tabular}{|c|c|c|c|c|}
\hline $\begin{array}{l}\text { Study and } \\
\text { design }\end{array}$ & Condition & Total duration & Intervention & $\begin{array}{l}\text { Author's } \\
\text { conclusion }\end{array}$ \\
\hline $\begin{array}{l}\text { Cacchio et al. }{ }^{17} \\
\text { RCT }\end{array}$ & $\begin{array}{l}\text { Complex } \\
\text { regional pain } \\
\text { syndrome }\end{array}$ & $\begin{array}{l}4 \text { weeks } \\
7 \text { days a week } \\
30 \text { minutes }\end{array}$ & $\begin{array}{l}\text { Patients performed all of the cardinal (proximal to distal) movements } \\
\text { of the affected arm }\end{array}$ & $\begin{array}{l}\text { Evidence of } \\
\text { effect }\end{array}$ \\
\hline $\begin{array}{l}\text { Cacchio et al. }{ }^{16} \\
\text { RCT }\end{array}$ & $\begin{array}{l}\text { Complex } \\
\text { regional pain } \\
\text { syndrome }\end{array}$ & $\begin{array}{l}\text { First } 2 \text { weeks } \\
5 \text { days a week } \\
30 \text { minutes } \\
\text { Last } 2 \text { weeks } \\
5 \text { days a week } \\
1 \text { hour }\end{array}$ & $\begin{array}{l}\text { Flexion and extension of the shoulder, elbow and wrist, and } \\
\text { pronosupination of the forearm }\end{array}$ & $\begin{array}{l}\text { Evidence of } \\
\text { effect and } \\
\text { effect } \\
\text { maintained } \\
\text { after } 6 \\
\text { months }\end{array}$ \\
\hline $\begin{array}{l}\text { Chan et al. }{ }^{18} \\
\text { RCT }\end{array}$ & $\begin{array}{l}\text { Phantom limb } \\
\text { pain }\end{array}$ & $\begin{array}{l}4 \text { weeks } \\
7 \text { days a week } \\
15 \text { minutes }\end{array}$ & Not specified & $\begin{array}{l}\text { Evidence of } \\
\text { effect }\end{array}$ \\
\hline $\begin{array}{l}\text { Brodie et al. }{ }^{28} \\
\text { RCT }\end{array}$ & $\begin{array}{l}\text { Phantom limb } \\
\text { pain }\end{array}$ & 1 session & $\begin{array}{l}\text { Patients attempted to perform the following movements: straighten } \\
\text { and bend the legs at the same time, and alternately. Point feet upwards, } \\
\text { and downwards. Turn soles in towards and away from each other. } \\
\text { Move feet in a circle. Lift feet off the ground in a walking movement. } \\
\text { Point toes upwards and downwards keeping ankle and foot still. } \\
\text { Clench, unclench, spread out and relax toes. Point up big toe and } \\
\text { point down the other toes, then reverse }\end{array}$ & $\begin{array}{l}\text { Evidence of } \\
\text { no effect }\end{array}$ \\
\hline $\begin{array}{l}\text { Michielsen et al. }{ }^{23} \\
\text { RCT }\end{array}$ & $\begin{array}{l}\text { Chronic pain } \\
\text { post stroke }\end{array}$ & $\begin{array}{l}6 \text { weeks } \\
5 \text { days a week } \\
1 \text { hour }\end{array}$ & $\begin{array}{l}\text { Participants performed bimanual exercises, with the difficulty of the } \\
\text { exercises depending on the patients' individual levels of functioning }\end{array}$ & $\begin{array}{l}\text { Evidence of } \\
\text { no effect }\end{array}$ \\
\hline $\begin{array}{l}\text { Dohle et al. }{ }^{19} \\
\text { RCT }\end{array}$ & $\begin{array}{l}\text { Severe } \\
\text { hemiparesis }\end{array}$ & $\begin{array}{l}6 \text { weeks } \\
5 \text { days a week } \\
30 \text { minutes }\end{array}$ & $\begin{array}{l}\text { Arm, hand and finger postures in response to verbal instructions, } \\
\text { protocol scaled according to the patients' level of performance }\end{array}$ & Not reported \\
\hline $\begin{array}{l}\text { Moseley }{ }^{21} \\
\text { RCT }\end{array}$ & $\begin{array}{l}\text { Complex } \\
\text { regional pain } \\
\text { syndrome type } 1\end{array}$ & $\begin{array}{l}2 \text { weeks } \\
7 \text { days a week } \\
10 \text { minutes for } \\
\text { each waking hour }\end{array}$ & $\begin{array}{l}\text { Patients were instructed to conduct smooth and pain-free movements } \\
\text { in accordance to pictures randomly presented }\end{array}$ & $\begin{array}{l}\text { Evidence of } \\
\text { effect in } \\
\text { combination } \\
\text { with GMI }\end{array}$ \\
\hline $\begin{array}{l}\text { Moseley }{ }^{20} \\
\text { RCT }\end{array}$ & $\begin{array}{l}\text { Complex } \\
\text { regional pain } \\
\text { syndrome type } 1\end{array}$ & $\begin{array}{l}2 \text { weeks } \\
7 \text { days a week } \\
10 \text { minutes for } \\
\text { each waking hour }\end{array}$ & $\begin{array}{l}\text { Patients were instructed to conduct smooth and pain-free movements } \\
\text { in accordance to pictures randomly presented }\end{array}$ & $\begin{array}{l}\text { Evidence of } \\
\text { effect in } \\
\text { combination } \\
\text { with GMI }\end{array}$ \\
\hline $\begin{array}{l}\text { Flinn et al. }{ }^{29} \\
\text { Non-randomized } \\
\text { controlled trial }\end{array}$ & $\begin{array}{l}\text { Phantom limb } \\
\text { pain }\end{array}$ & Not specified & Not specified & $\begin{array}{l}\text { Evidence of } \\
\text { no effect }\end{array}$ \\
\hline $\begin{array}{l}\text { McCabe et al. }{ }^{30} \\
\text { RCT }\end{array}$ & $\begin{array}{l}\text { Complex regional } \\
\text { pain syndrome }\end{array}$ & $\begin{array}{l}1 \text { session } \\
5 \text { minutes }\end{array}$ & $\begin{array}{l}\text { Flexion-extension cycles of both limbs with the range of movement } \\
\text { and speed dictated by the patients' pain }\end{array}$ & $\begin{array}{l}\text { Evidence of } \\
\text { effect }\end{array}$ \\
\hline $\begin{array}{l}\text { Michenthaler }{ }^{30} \\
\text { RCT }\end{array}$ & $\begin{array}{l}\text { Complex regional } \\
\text { pain syndrome }\end{array}$ & $\begin{array}{l}6 \text { weeks } \\
2 \text { days a week } \\
30 \text { minutes }\end{array}$ & Motor activities in 5 positions (not specified) & Not reported \\
\hline $\begin{array}{l}\text { Stein }^{26} \\
\text { RCT }\end{array}$ & $\begin{array}{l}\text { Phantom limb } \\
\text { pain }\end{array}$ & $\begin{array}{l}5 \text { days } \\
45 \text { minutes }\end{array}$ & Motor and sensory tasks (not specified) & Not reported \\
\hline $\begin{array}{l}\text { Acerra et al. }{ }^{27} \\
\text { RCT }\end{array}$ & Stroke & $\begin{array}{l}2 \text { weeks } \\
7 \text { days a week } \\
20 \text { to } 30 \text { minutes }\end{array}$ & $\begin{array}{l}\text { Functional motor tasks (i.e. with objects); motor coordination tasks; } \\
\text { sensory discrimination tasks; grip strength; active range of motion }\end{array}$ & Not reported \\
\hline
\end{tabular}

RCT: randomized controlled trial; GMI: graded motor imagery. 


\section{REFERENCES}

1. Elzahaf RA, Tashani OA, Unsworth BA, Johnson MI. The prevalence of chronic pain with an analysis of countries with a Human Development Index less than 0.9: a systematic review without meta-analysis. Curr Med Res Opin. 2012; 28(7):1221-9.

2. Cabral DM, Bracher ES, Depintor JD, Eluf-Neto J. Chronic pain prevalence and associated factors in a segment of the population of São Paulo City. J Pain. 2014; 15(11):1081-91.

3. Boyers D, McNamee P, Clarke A, Jones D, Martin D, Schofield P, et al. Costeffectiveness of self-management methods for the treatment of chronic pain in an aging adult population: a systematic review of the literature. Clin J Pain. 2013; 29(4):366-75.

4. Ramachandran VS, Rogers-Ramachandran D, Cobb S. Touching the phantom limb. Nature. 1995; 377(6549):489-90.

5. McCabe C. Mirror visual feedback therapy. A practical approach. J Hand Ther. 2011; 24(2):170-8.

6. Wand BM, Tulloch VM, George PJ, Smith AJ, Goucke R, O'Connell NE, et al. Seeing it helps: movement-related back pain is reduced by visualization of the back during movement. Clin J Pain. 2012; 28(7):602-8.

7. Boesch E, Bellan V, Moseley GL, Stanton TR. The effect of bodily illusions on clinical pain: a systematic review and meta-analysis. Pain. 2016; 157(3):516-29.

8. Ramachandran VS, Altschuler EL. The use of visual feedback, in particular mirror visual feedback, in restoring brain function. Brain. 2009; 132(Pt 7):1693-710.

9. Rothgangel A, Braun S, de Witte L, Beurskens A, Smeets R. Development of a clinical framework for mirror therapy in patients with phantom limb pain: an evidence-based practice approach. Pain Pract. 2016; 16(4):422-34.

10. Grünert-Plüss N, Hufschmid U, Santschi L, Grünert J. Mirror therapy in hand rehabilitation: a review of the literature, the St Gallen protocol for mirror therapy and evaluation of a case series of 52 patients. Hand Therapy. 2008; 13(1):4-11.

11. Casale R, Damiani C, Rosati V. Mirror therapy in the rehabilitation of lowerlimb amputation: are there any contraindications? Am J Phys Med Rehabil. 2009; 88(10):837-42.

12. Wittkopf PG, Johnson MI. Managing pain by visually distorting the size of painful body parts: is there any therapeutic value? Pain Manag. 2016; 6(3):201-4.

13. Moseley GL, Gallace A, Spence C. Bodily illusions in health and disease: physiological and clinical perspectives and the concept of a cortical 'body matrix'. Neurosci Biobehav Rev. 2012; 36(1):34-46.

14. Grant MJ, Booth A. A typology of reviews: an analysis of 14 review types and associated methodologies. Health Info Libr J. 2009; 26(2):91-108.

15. Rothgangel AS, Braun SM, Beurskens AJ, Seitz RJ, Wade DT. The clinical aspects of mirror therapy in rehabilitation: a systematic review of the literature. Int J Rehabil Res. 2011; 34(1):1-13.

16. Cacchio A, De Blasis E, De Blasis V, Santilli V, Spacca G. Mirror therapy in complex regional pain syndrome type 1 of the upper limb in stroke patients. Neurorehabil Neural Repair. 2009; 23(8):792-9.
17. Cacchio A, Blasis E, Necozione S, Orio F, Santilli V. Mirror therapy for chronic complex regional pain syndrome type 1 and stroke. N Engl J Med. 2009; 361(6):634-6.

18. Chan BL, Witt R, Charrow AP, Magee A, Howard R, Pasquina PF, et al. Mirror therapy for phantom limb pain. N Engl J Med. 2007; 357(21):2206-7.

19. Dohle C, Püllen J, Nakaten A, Küst J, Rietz C, Karbe H. Mirror therapy promotes recovery from severe hemiparesis: a randomized controlled trial. Neurorehabil Neural Repair. 2009; 23(3):209-17.

20. Moseley GL. Graded motor imagery is effective for long-standing complex regional pain syndrome: a randomised controlled trial. Pain. 2004; 108(1 2):192-8

21. Moseley GL. Graded motor imagery for pathologic pain: a randomized controlled trial. Neurology. 2006; 67(12):2129-34.

22. Bowering KJ, O'Connell NE, Tabor A, Catley MJ, Leake HB, Moseley GL, et al. The effects of graded motor imagery and its components on chronic pain: a systematic review and meta-analysis. J Pain. 2013; 14(1):3-13.

23. Michielsen ME, Selles RW, van der Geest JN, Eckhardt M, Yavuzer G, Stam $\mathrm{HJ}$, et al. Motor recovery and cortical reorganization after mirror therapy in chronic stroke patients: a phase II randomized controlled trial. Neurorehabil Neural Repair. 2011; 25(3):223-33

24. Thieme H, Morkisch N, Rietz C, Dohle C, Borgetto B. The efficacy of movement representation techniques for treatment of limb pain: a systematic review and meta-analysis. J Pain. 2016; 17(2):167-80.

25. Michenthaler M. Effectiveness of mirror therapy in complex regional pain syndrome (CRPS): a functional magnetic resonance imaging (fMRI) supported, double blinded RCT to the clinic-psychological status of affected patients before and after therapy [thesis]. Klagenfurt: Alpen-Adria-Universität Klagenfurt; 2013.

26. Stein R. Influence of non-pharmacological interventions (repetitive transcranial magnetic stimulation or mirror therapy) on pain intensity and pain associated central nervous plasticity in patients with phantom limb pain. Bochum: Ruhr-Universität Bochum; 2012.

27. Acerra NE. Is early post-stroke upper limb mirror therapy associated with improved sensation and motor recovery? A randomised-controlled trial. Sensorimotor dysfunction in CRPS1 and stroke: characteristics, prediction and intervention. Australia: University of Queensland; 2007.

28. Brodie EE, Whyte A, Niven CA. Analgesia through the looking-glass? A randomized controlled trial investigating the effect of viewing a 'virtual' limb upon phantom limb pain, sensation and movement. Eur J Pain. 2007; 11(4):428-36

29. Flinn SR, Hotle AC. A case series report on amputees with pro digit hand prostheses receiving mirror therapy. J Hand Ther. 2011; 24(4):390-1.

30. McCabe CS, Haigh RC, Ring EF, Halligan PW, Wall PD, Blake DR. A controlled pilot study of the utility of mirror visual feedback in the treatment of complex regional pain syndrome (type 1). Rheumatology (Oxford). 2003; 42(1):97-101.

31. Pervane Vural SP, Nakipoglu Yuzer GF, Sezgin Ozcan D, Demir Ozbudak $\mathrm{S}$, Ozgirgin N. Effects of mirror therapy in stroke patients with complex regional pain syndrome type 1: a randomized controlled study. Arch Phys Med Rehabil. 2016; 97(4):575-81. 